\title{
A study on knowledge and practices of antenatal care among pregnant women attending antenatal clinic at a tertiary care hospital, Gujarat, India
}

\author{
Rohit Jain $^{1}$, Chintan Upadhyay ${ }^{2 *}$, Bipin Nayak ${ }^{1}$
}

\begin{abstract}
${ }^{1}$ Department of Obstetrics and Gynecology, GMERS Medical College and Civil Hospital, Gandhinagar, Gujarat, India ${ }^{2}$ Department of Obstetrics and Gynecology, Dr. N. D. Desai Faculty of Medical Science and Research Institute, Gujarat, India
\end{abstract}

Received: 25 November 2019

Accepted: 16 December 2019

\author{
*Correspondence: \\ Dr. Chintan Upadhyay, \\ E-mail: docrohitjain270378@gmail.com
}

Copyright: () the author(s), publisher and licensee Medip Academy. This is an open-access article distributed under the terms of the Creative Commons Attribution Non-Commercial License, which permits unrestricted non-commercial use, distribution, and reproduction in any medium, provided the original work is properly cited.

\begin{abstract}
Background: Improving maternal health is one of the eight-millennium development goals (MDGs). Since 1990, maternal deaths worldwide have dropped by $47 \%$. This study aimed to determine the level of knowledge, attitude, and practice on ANC among pregnant women attending the antenatal clinic at a tertiary care hospital in Gujarat and their association with various sociodemographic factors.

Methods: A cross-sectional study was carried out among 384 pregnant women in their $3^{\text {rd }}$ trimester attending the antenatal clinic in a tertiary care hospital of Gujarat during April 2018 to September 2018. Pretested questionnaire was used for collecting data by interview after obtaining informed consent. Statistical analysis was performed using SPSS version 20 and Epi Info software.

Results: Study reveals that about 58\% women had adequate knowledge regarding ANC. It was found that almost all the variables such as age, education, occupation, parity, type of family, and socioeconomic status (SES) had a significant association with awareness about ANC. 100\% women were having a positive attitude toward ANC. Around 70\%, women were practicing adequately, and variables such as education and SES had a significant association with practices about ANC.

Conclusions: These findings can be used to plan a health intervention program aiming to improve the maternal health practices and eventually improve the health status of the women.
\end{abstract}

Keywords: Antenatal care, Knowledge, Practice, Pregnant women, Tertiary care hospital

\section{INTRODUCTION}

Safe motherhood Initiatives, launched by the World Health Organization in 1987 which aimed to reduce the number of deaths associated with pregnancy and childbirth. ${ }^{1}$ Appropriate antenatal care (ANC) is one of the important components of this initiative which is an important element in maternal healthcare as appropriate care will lead to successful pregnancy outcome and healthy babies. Improving maternal health is one of the eight-millennium development goals (MDGs). Since
1990, maternal deaths worldwide have dropped by $47 \% .^{2}$ In India data from the most recent National family health survey-3 suggest that the maternal mortality ratio has fallen from approximately 212 per 100,000 live births in 2007-09 to 167 deaths per 100,000 live births in 2011$13 .^{3}$ The maternal mortality ratio (MMR) in India has been maintained at a higher level since long. It is very high compared to the international scenario like Sweden (5), USA (24), and Brazil (58) and even in neighbouring countries such as Sri Lanka (39) and Thailand (48). ${ }^{4}$ Although the health status of women has improved over 
the years due to concentrated efforts of Government of India, it is still not at par with the international benchmark and is unacceptably high. Health outcome goals established in the $13^{\text {th }} 3$-year plan are to reduce infant mortality rate to 30 per 1000 live births, to reduce maternal mortality ratio to 120 per 100,000 live births by $2020 .^{5}$

\section{Aim}

- To improve maternal health, barriers that limit access to quality maternal health services must be identified and addressed at all levels of the health system. Health knowledge is an important element to enable women to be aware of their health status and the importance of appropriate ANC. Very few studied are carried out in India about this aspect of maternal health and hence data in this regard is scarcely available. ${ }^{6}$

- To determine the level of knowledge, attitude, and practice related to ANC among these pregnant women and to assess the awareness about their own health during pregnancy.

\section{METHODS}

This was a cross-sectional study done at obstetrics and gynecology department, GMERS medical college and civil hospital, Gandhinagar during April 2018 to September 2018 after taking permission from Institutional Ethical Committee (IEC) of GMERS Medical College, Gandhinagar. Study enrolled 384 pregnant women who attended OPD at obstetrics and gynecology department after obtaining written consent selected by systemic random sampling. Exclusion and inclusion criteria: study had included all the ANC who gave consent for participation in study.

Knowledge will be assessed about ANC visits, tetanus immunization, investigations, and nutritional factors, danger signs of pregnancy, contraception, and personal habits. Each parameter will be awarded 1 mark for the correct answer and 0 mark if the answer will be wrong. Thus, total marks for questions related to knowledge will be 44 . Those who scored $70 \%$ and above will be considered as having adequate knowledge, and those who scored below $70 \%$ will be considered inadequate knowledge.

Variables to assess attitude will be an opinion on the place of delivery, the effect of smoking on mother and fetus and effects of alcohol on the health of mother and fetus, ANC registration, visits, motivation, investigations, dietary changes, and iron and folic acid (IFA) intake and its regularity in the intake. Also smoking, alcohol and drug intake, medical problems, and use of contraception. Each attitude questionnaire will be scaled using 5-point likert scale.
Total score for questions related to attitude will be carrying 75 marks. Those who scored $70 \%$ and above will be considered as having a good attitude toward ANC. Questions will be asked to assess the practices with regards to ANC visit, dietary changes made during pregnancy, IFA tablets taken. Questions related to smoking, alcohol, self-medication will be noted. Tetanus immunization during pregnancy and practice with regard to use of contraception will be also noted. Each parameter will be awarded 1 mark for good practice and 0 marks if the practice will be not found appropriate. Thus, total marks for questions related to practices will be 21 . Practice on attending number of visits carried 2 marks $(<$ 3 visits $=0,3-5$ visits $=1$ and $>5$ visits $=2)$. Practice of IFA tablet consumption carried 5 marks $(0-49=1,51-99$ $=2,100-149=3,150-200=4,>200=5$ ). Those who scored $70 \%$ and above will be considered as practicing adequately and those who scored below $70 \%$ will be considered inadequate practices with regard to ANC. Demographic characteristics namely age, parity, type of family, education and occupation, and socioeconomic status (SES) will be selected for studying association with knowledge and practices regarding ANC. For the ease of study, age is categorized into two categories namely age $<20$ years and $\geq 20$ years. Family will be divided into two categories namely joint family and other. Education will be categorized divided into those below $10^{\text {th }}$ standard and more than $10^{\text {th }}$ standard. Occupation will be divided as unemployed and employed. Study participants will be divided into two categories; $1^{\text {st }}$ up to upper lower class and $2^{\text {nd }}$ category included more than the lower middle of Kuppuswamy Scale. ${ }^{7}$

\section{Statistical analysis}

The data were recorded in an Excel sheet and descriptive analysis was performed, of which data are presented in the tables.

\section{RESULTS}

Out of 384 study participants $201(52.3 \%)$ study subjects had adequate knowledge about overall ANC care. Almost $99.0 \%$ women scored more than $70 \%$ marks with mean of $85.2 \%$ and standard deviation 9.1 meaning they have an adequate attitude toward ANC care. $69.3 \%$ study subjects followed adequate ANC practices (Table 1).

Tables 2 and 3 summarize the association of knowledge and practices regarding ANC with sociodemographic factors. There was significant association found between age and overall knowledge about ANC $(\mathrm{P}=<0.05$ includes 1). There was no significant relation found between type of family and overall Knowledge about ANC ( $P>0.05)$. It is clearly evident that knowledge is not significantly associated with increasing parity (Chisquare, $\mathrm{P}>0$ ). Although both groups were having knowledge about ANC care but it was associated more closely with those women who were more educated (more than $10^{\text {th }}$ class). (Chi-square test, $\mathrm{P}<0.05$ ). 
Table 1: Score based on knowledge attitude and practices regarding ANC among study subjects.

\begin{tabular}{|llll|}
\hline Score $(\%)$ & $\begin{array}{l}\text { Frequency } \\
\text { Knowledge }\end{array}$ & Attitude & Practice \\
\hline Adequate/good $(>70 \%)$ & $201(52.3)$ & $380(99.0)$ & $280(72.9)$ \\
\hline Inadequate/poor $(<70 \%)$ & $183(47.7)$ & $4(1.0)$ & $104(27.1)$ \\
\hline Total & $\mathbf{3 8 4}$ & $\mathbf{3 8 4}$ & $\mathbf{3 8 4}$ \\
\hline Mean score & $71.5 \%$ & $85.2 \%$ & $76.8 \%$ \\
\hline SD & 16.1 & 9.1 & 11.1 \\
\hline
\end{tabular}

Table 2: Association of overall knowledge regarding ANC with sociodemographic factors.

\begin{tabular}{|c|c|c|c|c|}
\hline \multirow{2}{*}{ Parameter } & \multirow{2}{*}{ Number $(\%)$} & \multicolumn{2}{|l|}{ Knowledge } & \multirow{2}{*}{ p-value } \\
\hline & & Adequate & Inadequate & \\
\hline \multicolumn{5}{|l|}{ Age } \\
\hline$>20$ & 315 & 193 & 122 & \multirow{2}{*}{$<0.05$} \\
\hline$\leq 20$ & 69 & 30 & 39 & \\
\hline \multicolumn{5}{|l|}{ Family } \\
\hline Joint & 242 & 144 & 98 & \multirow{2}{*}{$>0.05$} \\
\hline Others & 142 & 78 & 64 & \\
\hline \multicolumn{5}{|l|}{ Parity } \\
\hline Multi & 201 & 119 & 82 & \multirow{2}{*}{$>0.05$} \\
\hline Primi & 183 & 104 & 79 & \\
\hline \multicolumn{5}{|l|}{ Education } \\
\hline$>10$ & 174 & 135 & 39 & \multirow{2}{*}{$<0.05$} \\
\hline$<10$ & 210 & 88 & 122 & \\
\hline \multicolumn{5}{|l|}{ Occupation } \\
\hline Working & 30 & 26 & 4 & \multirow{2}{*}{$<0.05$} \\
\hline Non-working & 354 & 197 & 157 & \\
\hline \multicolumn{5}{|l|}{ SES } \\
\hline Middle and upper & 230 & 161 & 69 & \multirow{2}{*}{$<0.05$} \\
\hline Lower & 154 & 80 & 74 & \\
\hline
\end{tabular}

Table 3: Association between selected demographic factors with overall ANC practices.

\begin{tabular}{|c|c|c|c|c|}
\hline \multirow{2}{*}{ Parameter } & \multirow{2}{*}{ Number (\%) } & \multicolumn{2}{|c|}{ Practice } & \multirow{2}{*}{ p-value } \\
\hline & & Good & Poor & \\
\hline \multicolumn{5}{|l|}{ Age } \\
\hline$>20$ & 315 & 215 & 100 & \multirow{2}{*}{$>0.05$} \\
\hline$\leq 20$ & 69 & 20 & 49 & \\
\hline \multicolumn{5}{|l|}{ Family } \\
\hline Joint & 242 & 174 & 68 & \multirow{2}{*}{$>0.05$} \\
\hline Others & 142 & 90 & 52 & \\
\hline \multicolumn{5}{|l|}{ Parity } \\
\hline Multi & 201 & 145 & 56 & \multirow{2}{*}{$>0.05$} \\
\hline Primi & 183 & 121 & 62 & \\
\hline Education & & & & $<0.05$ \\
\hline$>10$ & 174 & 135 & 39 & \\
\hline$<10$ & 210 & 88 & 122 & \\
\hline \multicolumn{5}{|l|}{ Occupation } \\
\hline Working & 30 & 22 & 8 & \multirow{2}{*}{$>0.05$} \\
\hline Non-working & 354 & 244 & 110 & \\
\hline \multicolumn{5}{|l|}{ SES } \\
\hline Middle and upper & 230 & 175 & 55 & \multirow{2}{*}{$<0.05$} \\
\hline Lower & 154 & 111 & 43 & \\
\hline
\end{tabular}


Although the adequate knowledge women were distributed among both employed and unemployed women, but it was more associated with employed women. It means that working women were more knowledgeable than unemployed women (Chi-square, $\mathrm{P}$ $<0.05)$. There was significant relation found between SES and overall knowledge about ANC (Chi-square, $\mathrm{P}<$ $0)$. Similar trends were noted between SES and practices regarding ANC.

Table 4 shows association between level of knowledge and practice. There was a significant association between knowledge of ANC and practice. Those who had adequate knowledge about ANC care they had adopted good practice $(\mathrm{P}<0.05)$.

Table 4: Association between knowledge and practice about ANC care.

\begin{tabular}{|lll|l|}
\hline Knowledge & $\begin{array}{l}\text { Practice } \\
\text { Good }\end{array}$ & Poor & P-value \\
\hline Adequate & 198 & 31 & \multirow{2}{*}{$<0.05$} \\
\hline Inadequate & 84 & 71 & \\
\hline
\end{tabular}

\section{DISCUSSION}

In our study, mean age for respondents was 24 years with age range from 18 to 37 years. Our study showed that statistically significant association between age and knowledge about ANC but not with overall ANC practices. A study done by Sanjel et al, Tamang also shows a significant association between age and knowledge. ${ }^{8}$

A study done by Sanjel et al, shows a significant association between numbers of pregnancy and ANC visits during most recent pregnancy at $95 \%$ level of confidence $(\mathrm{P}<0.05)$ whereas no such association was found in our study. Agarwal et al, in their study found that ANC received was significantly lower among illiterate women. This finding is similar with our finding in which women who were more educated were better aware about almost all the factors of ANC. However, women with lower education $\left(<10^{\text {th }}\right)$ were performing better in term of visits and women with higher education $\left(>10^{\text {th }}\right.$ ) were doing better practice with regards to nutrition and other factors. Overall educated women were practicing in a better way than non-educated women. ${ }^{9}$

Our study findings were comparable with a study done by Al-Shammari et al, which found that educated mothers and mothers aged $<20$ years had more prenatal visits which was similar to our study findings. ${ }^{10}$ Similarly, working women were better aware about almost all the factors of ANC. But it was not uniform with regard to practice. Nonworking women were doing better practice with regards to antenatal visits, rest, etc., whereas working women were practicing in a better way than nonworking women with regards to nutritional aspects.
However, overall there was no significant association found between education and practice $(\mathrm{P}>0.05)$.

Present study also found a significant association between Socioeconomical status and awareness about almost all the factors of ANC. With regard to practice; women from high socioeconomic class were doing better practice with regards to nutrition but women from low socioeconomic class were doing better practice with regard to visits and other care. Overall, women with the higher socioeconomic class were practicing better $(\mathrm{P}<$ 0.05). There are few limitations of this study. Findings of the study can only be extrapolated on urban women who are attending antenatal services, and there is a possibility of recall bias among study participant. Different findings might be seen if the study is conducted among the other places due to different cultural practices, norms and belief. However, this study may act as a preliminary survey due to the scarcity of published data regarding the ANC care.

\section{CONCLUSION}

The still higher proportion of $(47.7 \%)$ of pregnant women has inadequate knowledge, and about one-third of study participant have poorly practice ANC care. Their knowledge on certain aspects of ANC were still poor especially regarding the importance of early antenatal check-up, health screening and complications related to diabetes and hypertension in pregnancy. Specific intervention program needs to be planned and conducted to improve their maternal health practices and eventually improve the health status of women in the society.

\section{Funding: No funding sources \\ Conflict of interest: None declared}

Ethical approval: The study was approved by the Institutional Ethics Committee

\section{REFERENCES}

1. World Bank. Safe Motherhood - A Review. The Safe Motherhood Initiatives, 1987-2005 World Bank Report. New York: Family Care International; 2007.

2. United Nations. The Millennium Development Goals Report 2011. New York: United Nations; 2015.

3. International Institute for Population Sciences and Macro International, National Family Health Survey (NFHS-3) 2005-06: Vol. 1. India; 2007. Available at: http://www.measuredhs.com/pubs/pdf/FRIND3/01C hapter01.pdf. Accessed on $3^{\text {rd }}$ May 2019.

4. WHO, UNICEF UNFPA, The World Bank. Trends in Maternal Mortality 1990 to 2008. Geneva: WHO Press 2010. Available at: https://www.who.int/reproductivehealth/publications /monitoring/9789241500265/en/. Accessed on $10^{\text {th }}$ October 2019.

5. The three-year action agenda, a NITI Aayog document. Published by NITI Aayog Sansad Marg, New Delhi; 2017. Available at: 
http://planningcommission.nic.in/reports/sereport/ser /stdy_immm.pdf. Accessed on 10 ${ }^{\text {th }}$ October 2019.

6. World Health Organization. Maternal mortality: fact sheet: to improve maternal health, barriers that limit access to quality maternal health services must be identified and addressed at all levels of the health system; 2014. Available at: https://apps.who.int/iris/handle/10665/112318.

Accessed on $30^{\text {th }}$ September 2019.

7. Kumar N, Gupta N, Kishore J. Kuppuswamy's socioeconomic scale: Updating income ranges for the year 2012. Indian J Public Health. 2012;56:103-4.

8. Sanjel S, Ghimire RH, Pun K. Antenatal care practices in Tamang community of hilly area in central Nepal. Kathmandu Univ Med J (KUMJ). 2011;9:57-61.
9. Agarwal P, Singh MM, Garg S. Maternal health-care utilization among women in an urban slum in Delhi. Indian J Community Med. 2007;32:203-5.

10. Al-Shammari SA, Khoja T, Jarallah JS. The pattern of antenatal visits with emphasis on gestational age at booking in Riyadh Health Centres. J R Soc Health. 1994;114:62-6.

Cite this article as: Jain R, Upadhyay C, Nayak B. A study on knowledge and practices of antenatal care among pregnant women attending antenatal clinic at a tertiary care hospital, Gujarat, India. Int J Reprod Contracept Obstet Gynecol 2020;9:60-4. 